\title{
EWES AND LAMBS BEHAVIOURAL RESPONSES TO CHANGES IN LAMB'S COAT COLOUR: I. BLACKENING OF A PART OR WHOLE BODY IN EGYPTIAN BARKI SHEEP
}

Abd-Alla, M. S. ; Rania Agamy and A.Y. Abdel-Moneim

Dept. of Animal Production, Fac. Agric., Cairo University, Giza-Egypt.

\begin{abstract}
Twenty eight Barki ewes with their lambs were used to examine the effect of blackening of a part (whole body except head, rump with tail,around eyes and head) or whole body of lambs on maternal responsiveness of Barki (white breed) ewes during the $2 \frac{\text { nd }}{}$ week after lambing. Ewes and lambs were separated (50 m away from each other) for 4 hours before test period. Behavioural displayes of dams and lambs were recorded for $10 \mathrm{~min}$ when lambs were introduced to dams. Blackening of a part or whole body of lambs reduced significantly $(P<0.01)$ number of acceptances at the udder compared with unblackened ones. Number of rejections at udder was significantly $(\mathrm{P}<0.05)$ less in unblackened lambs and those lambs with blackened eye region or blackened head. Lambs blackened, whole body except head, paced significantly $(\mathrm{P}<0.05)$ longer distance towards their dams. Lambs completely or partially blackened, including those with black rump, eye region or head, followed, respectively, in this order. Meanwhile, blackening treatment had a significant $(P<0.05)$ effect on number of suckling attempts. The highest number of suckling attempts was exhibited by the completely black lambs, followed, respectively, by those of black rump and those with black body excluding head. Less suckling attempts were observed by lambs with black head and those with black region of the eyes. It could be deduced that vision seems to play an important role in discrimination between ewes and their lambs at the early stages of lamb's life.
\end{abstract}

Keywords: Maternal behaviour, blackening, Barki lambs, visual cue.

\section{INTRODUCTION}

Maternal behaviour in sheep, like in many ungulates, is characterized by a rapid development of exclusive bonding to the neonate. Mother can identify her young through the use of different sensory modalities, but the sensory basis for proximal recognition of lamb differs from that mediating distal recognition. Olfactory discrimination by the mother appears limited to a very short range "less than $0.25 \mathrm{~m}$ " ( Keller et al ., 2003 ), and at longer distance recognition appears to depend on either visual or acoustic cues. In this context, Hart ( 1985 ) indicated that some of the major senses are used relatively infrequently, but vision is involved to some extent in the perception of most stimuli and has been shown to be the dominant sense in many situations. Changing the visual appearance of lambs interferes with the mother's ability to identify their own lambs and they may reject them. Alexander and Shillito ( 1978 a) found that the ewes showed marked abnormalities of maternal behaviour such as vigorous avoidance of the approaching lamb which had 
Abd-Alla, M.S. et al.,

been coloured by brushing pigments into the coat. The aim of this work was to study the responses of the mothers towards their lambs with blackened body regions at the early stages of lamb's life.

\section{MATERIALS AND METHODS}

\section{Animals and experimental procedures:}

This study was carried out at the Sheep and Goats farm of the Faculty of Agriculture, Cairo University, Giza, Egypt, during the lambing season extended from early October to late December, 2006.

\section{Blackening of Barki lambs trial:}

Animals used were 28 white Barki ewes with their lambs (25 multiparous,3-5 years old and 3 primiparous, 1.5- 2 years old). The average body weight of the primiparous and multiparous ewes was $34 \mathrm{~kg}$ and 41 $\mathrm{kg}$, respectively. At the second week postpartum, 28 Barki lambs (completely white head and body) were allocated into six trial groups ( Table 1). Lambs were randamly assigned as suggested by Alexander and Shillito (1977 b) to the following groups, each group consisted of ewes and their lambs: a)-Unblackened (control) lamb group (6 lambs and their 6 ewes, Fig. 1a). b)-Completely blackened whole body lamb group (6 lambs and their 6 ewes, Fig. 1b). c)- The whole body blackened except head of lamb group (3 lambs and their 3 ewes, Fig. 1c). d)- The head only blackened lamb group (4 lambs and their 4 ewes, Fig. 1d). e)- A blackened circle of approximately $4 \mathrm{~cm}$ radius round each eye of lamb group (6 lambs and their 6 ewes, Fig. 1e). f)-The posterior $10 \mathrm{~cm}$ of the trunk " rump" with the tail of lamb blackened group (3 lambs and their 3 ewes, Fig. 1f).

\section{Table (1): Blackening trials of Barki lambs.}

\begin{tabular}{|c|c|c|c|}
\hline $\begin{array}{l}\text { No.of } \\
\text { group }\end{array}$ & $\begin{array}{l}\text { No.of } \\
\text { lambs }\end{array}$ & Trial & $\begin{array}{l}\text { No.of } \\
\text { figure }\end{array}$ \\
\hline 1 & 6 & a)-No blackening of lamb (control). & $1 \mathrm{a}$ \\
\hline 2 & 6 & b)-Completely blackened whole body. & $1 b$ \\
\hline 3 & 3 & c)-Blackening the whole body except head. & $1 \mathrm{c}$ \\
\hline 4 & 4 & d)- Blackening the head only. & $1 d$ \\
\hline 5 & 6 & $\begin{array}{l}\text { e)- Blackening a circle of approximately } \\
4 \mathrm{~cm} \text { radius round each eye. }\end{array}$ & $1 \mathrm{e}$ \\
\hline 6 & 3 & $\begin{array}{l}\text { f)- Blackening the posterior } 10 \mathrm{~cm} \text { of the } \\
\text { trunk " rump "with the tail. }\end{array}$ & $1 \mathrm{f}$ \\
\hline
\end{tabular}




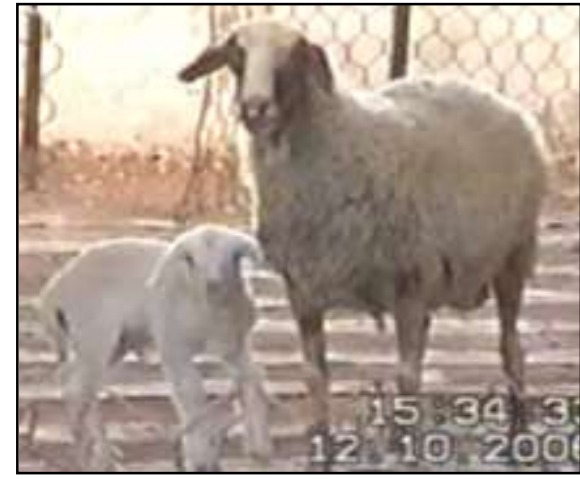

(a): Control unblackened lamb.

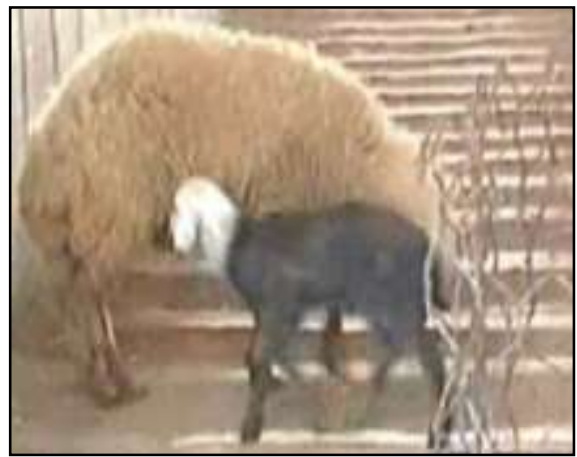

(c): Blackened whole body except head of lamb.

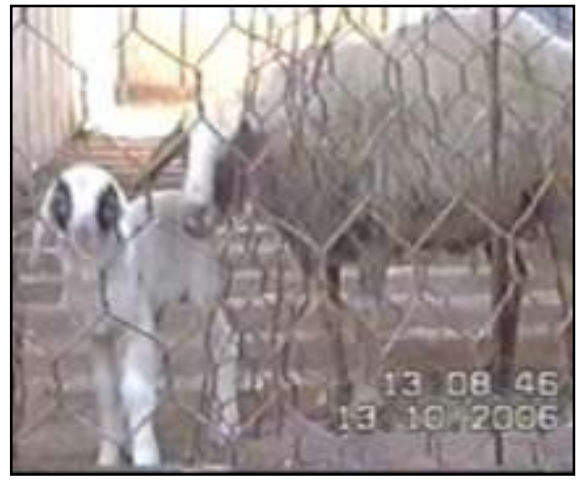

(e): Blackened around eyes of lamb.

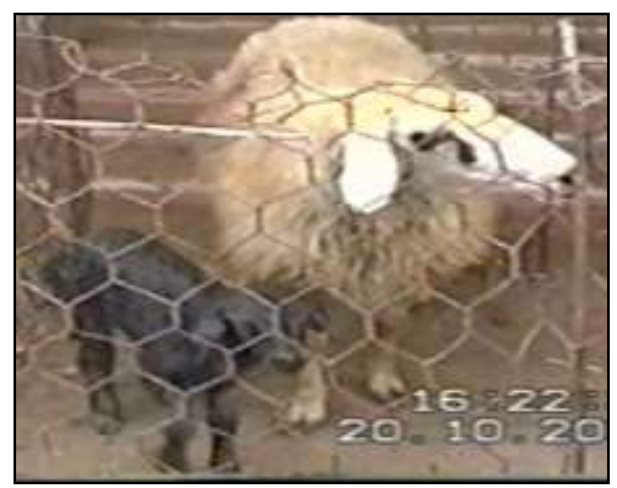

(b): Blackened whole body of lamb.

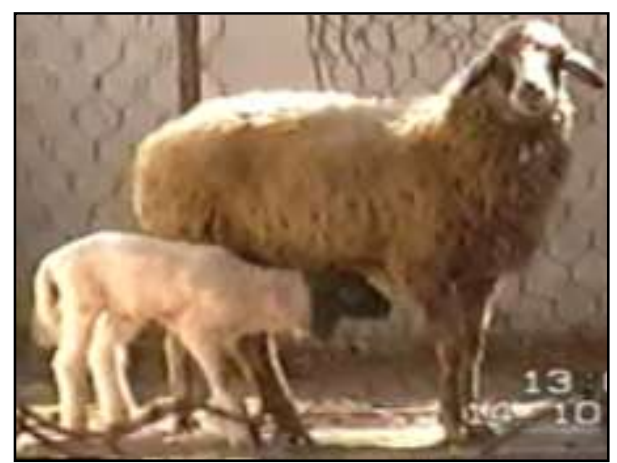

(d): Blackened head of lamb.

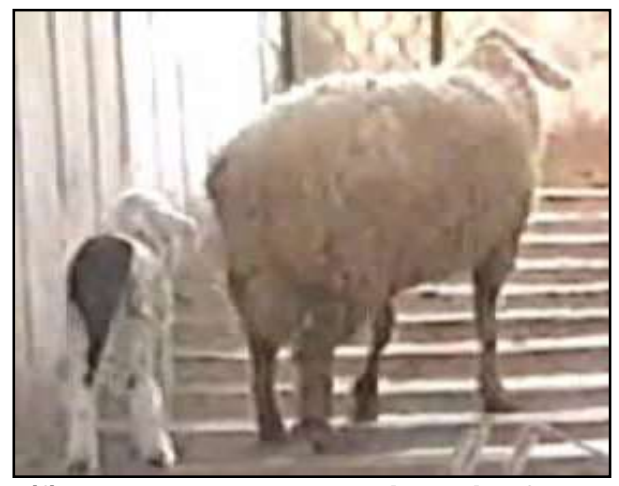

(f): Blackened rump with tail of lamb.

Fig. (1): Blackening all or some parts of body of the white Barki lambs. 
Abd-Alla, M.S. et al.,

\section{Housing system:}

Following parturition and throughout the test period, ewes and their lambs were housed in $23.25 \times 6.60 \mathrm{~m}$ pen with a $1.6 \mathrm{~m}$ high fence and a $3.5 \mathrm{~m}$ high roof with a soil floor. The pen had two built in troughs averages of $12 \times 0.5 \times 0.3 \mathrm{~m}$. All observations were recorded using a video camera (Panasonic VHS-C Movie camera NV-VZ18GC/GCS, $16 \mathrm{~mm}, 800 \times$ digital zoom, Malaysia). This video camera was fixed 1.35 $\mathrm{m}$ high and $2 \mathrm{~m}$ away from the mother's test cage. During test periods, ewes were exposed to normal daylight, while two fluorescent lamps (TL40W/54) were used by night to illuminate the enclosure area and cages and to give sufficient light for the camera to record clear pictures. The tests were carried out in an enclosure area of $1.8 \times 10 \mathrm{~m}$ with $1.6 \mathrm{~m}$ high fence far from any source of disturbance. There were two wire mesh cages at terminals of the enclosure. The first (ewe cage) was $1.2 \times 1.2 \mathrm{~m}$ with $1.25 \mathrm{~m}$ high fence and a wire mesh door. Whereas the second, lamb cage, was $1.8 \times 0.7 \mathrm{~m}$ located at the opposite side in front of the video camera (Fig. $2 \mathrm{a}$ and b). These arrangements made it easy for the observer to clearly watch the animals.

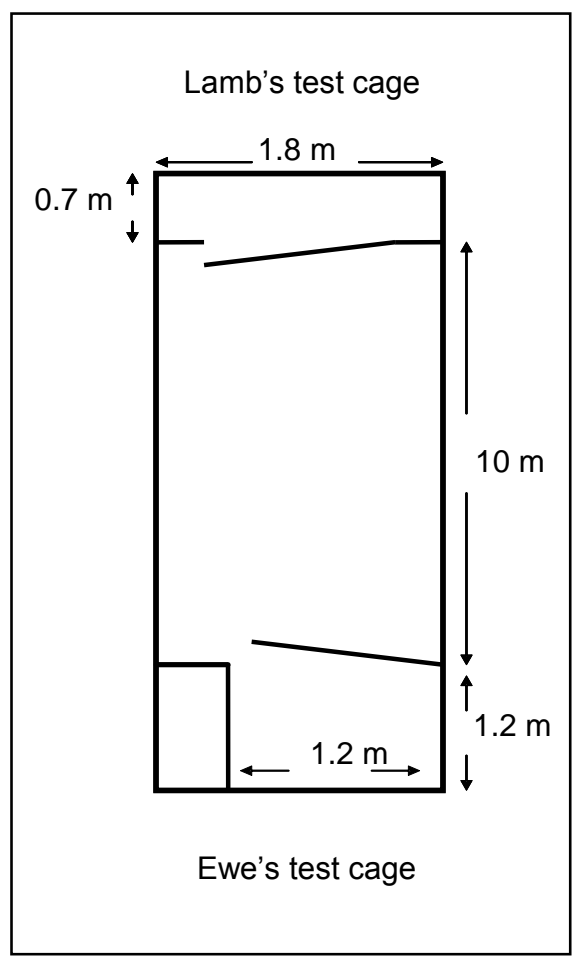

(a)

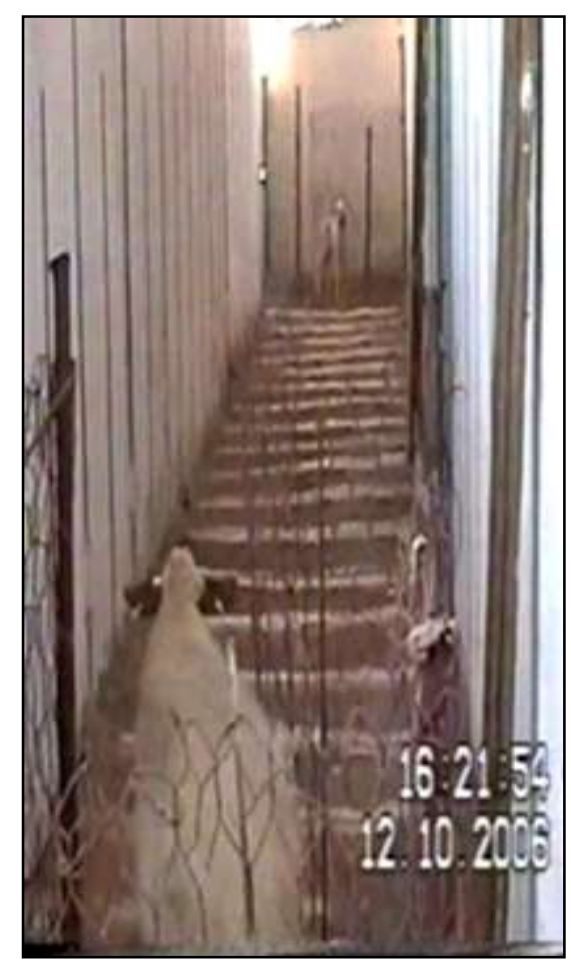

(b)

Fig. (2): a) Dimensions of enclosure area and test ewe's and lamb's cages.

b) Actual view of enclosure area during the test. 


\section{Feeding system:}

During pregnancy and up to 6 weeks before lambing, ewes were fed ad libitum on Darawa (Zea maize L.) and Egyptian clover hay. In addition, each ewe was supplemented with a daily allowance of $500 \mathrm{~g}$ of a concentrate mixture. This concentrate mixture consisted of $55 \%$ yellow corn, $25 \%$ wheat bran, $15 \%$ soybean meal, $3 \%$ limestone, $1 \%$ sodium chloride and $1 \%$ common salt. During the last 6 weeks of pregnancy, each ewe received liberal amount of hay and a daily amount of $750 \mathrm{~g}$ of the concentrate mixture. After parturition, ewes were fed ad libitum on a mixture of Egyptian clover (Trifolium alexandrinum) and rice straw and each ewe was supplied with $750 \mathrm{~g} /$ day of the concentrate mixture. Water and salt blocks were available for the animals all time.

At the test day, lambs were separated 50 meter away from their dams. Isolation lasted for 4 hours as suggested by Alexander and Shillito(1977a) to induce rapid suckling and to stimulate suckling desire at the beginning of the test. After the isolation period, each ewe was placed in a cage $1.2 \times 1.2 \mathrm{~m}$ with $1.25 \mathrm{~m}$ high fence and a wire mesh door. At the same time, its lamb was entered to a cage $1.8 \times 0.7 \mathrm{~m}$ located at the opposite side in front of the video camera. By the end of the 4 hours isolation period, the ewe and its lamb were released from opposite ends of the enclosure. Behavioural acts of both mother and her lamb were observed and recorded for 10 min as follows:

\section{Behavioural displays of ewes towards lambs:}

\section{Positive maternal behaviour displays:}

The following behavioural parameters were recorded: a)-latency to first attentiveness (sniffing and licking different parts of young's body) by dam (min), b)-frequency of attentiveness by ewe (count), c)- time of attentiveness to lamb (min), d)-number of acceptance at the udder during suckling attempts (count), e)- number of low-pitched bleats (count), f)distance by dam towards the lamb (distance that was covered by dam towards the lamb to join with (meet) each other in enclosed area "10 m") (meter). These parameters were indicative of acceptance of the lamb.

Negative maternal behaviour displays:

These displays included: a)- number of high-pitched bleats ( times of mother vocalization made with mouth open. (count), b)- number of rejections at udder during suckling attempts (count), c)-number of threats and head butts directed towards the lamb (count). These parameters indicated lamb rejection.

Behavioural displays of lambs towards ewes:

The following behavioural parameters were recorded: a)- distance by lamb towards the dam (distance covered by lamb towards the dam to join with each other in enclosed area "10 m") (meter), b)- latency of first suckling during test period ( $\mathrm{min}), \mathrm{c}$ )- suckling time ( $\mathrm{min}), \mathrm{d}$ )- number of suckling attempts (count), e)-number of baaings (times of high bleats of young) (count).

The maternal and neonatal parameters recorded for each dam and offspring for $10 \mathrm{~min}$ following isolation for 4 hours period were 
Abd-Alla, M.S. et al.,

measured according to Vince et al. (1987), Pfister et al. ( 2006 ) and Abdel-Moneim and Abd-Alla (2006).

Statistical analysis of data:

The influences of blackening of white Barki sheep on maternal and lamb behaviour parameters were analyzed using the GLM procedure analysis of variance for repeated measures. This effect was assumed fixed except the random error, which was assumed normally and independently distributed with mean 0 and variance $\sigma^{2}$. Significant differences among means were detected using the Duncan's Multiple Range Test (SAS, 1998).

\section{RESULTS AND DISCUSSION}

\section{Behavioural displays of ewes towards lambs:}

\section{Positive maternal behaviour displays:}

It is apparent from Table 2 that latency to first attentiveness was significantly $(P<0.05)$ longer when the lambs were blackened completely except head than the rump with tail had been blackened. The obviously black appearance of the body seemed to be stranger to the mother. However, no significant differences in latency to first attentiveness, frequency of attentiveness to lamb as well as time of attentiveness to lamb were observed among the different groups (Tables 2 and 3). Similar observations were recorded by Alexander (1977) who indicated that ewes' scores for interest in lambs were reduced by blackening. Blackening of part or whole body of lamb reduced number of acceptances at the udder (Table 2). Table 2 also revealed a clear trend to decrease acceptance of lambs at the udder with increased blackening of lamb's body. The differences reached significant levels for all treatments, except those lambs with black area around the eye (Tables 2 and 3). The strange appearance of the blackened lambs obviously reduced acceptance at the udder. This might be interpreted to mean that vision seems to play an important role in discrimination of lambs by ewe at the early stages of lamb's life. These findings received confirmation from Alexander and Shillito (1977 b) who reported that colour changes of the lamb made the ewe to behave as if own lamb was an alien. Number of low-pitched bleats, and distances covered by ewes did not change significantly by blackening part or whole body of the lamb (Table 3). Nevertheless, Table 2 clearly shows that lambs with blackened body, except head did not receive any low-pitched bleats from their dams. Furthermore, only $17 \%$ of ewes with completely blackened lambs emitted low-pitched bleats (Table 2). In this context, only $33 \%$ of ewes with blackened body lambs, except head paced shorter distance towards their lambs than the distances covered by ewes in other treated and untreated groups (Table 2). Similar observations were reported by Alexander (1977) who showed that blackening of lambs caused confusion of the ewe's approach, or even dodging lamb. 
J.Animal and Poultry Prod., Mansoura Univ., Vol.2(10), October,2011

Table 2 
Abd-Alla, M.S. et al.,

Table (3): Analysis of variance for the effect of blackening all or a part of lamb's body on maternal and lamb behaviour displays.

\begin{tabular}{|l|c|c|c|c|}
\hline \multirow{2}{*}{\multicolumn{1}{c|}{ Behaviour displays }} & \multicolumn{3}{c|}{ Source of variation } \\
\cline { 2 - 5 } & \multicolumn{2}{c|}{ Treatment } & \multicolumn{2}{c|}{ Residual } \\
\cline { 2 - 5 } & d.f. & M.S. & d.f. & M.S. \\
\hline Dam behaviour displays: & & & & \\
Positive maternal behaviour & & & \\
Latency to first attentiveness & 5 & 0.002 & 22 & 0.001 \\
Frequency of attentiveness to lamb & 5 & 123.08 & 22 & 291.44 \\
Time of attentiveness to lamb & 5 & 0.71 & 22 & 0.69 \\
No.of acceptance at the udder & 5 & $53.19^{* *}$ & 15 & 5.65 \\
No.of low-pitched bleats & 4 & 24.03 & 12 & 41.07 \\
Distance by dam towards the lamb & 5 & 5.22 & 19 & 7.85 \\
Negative maternal behaviour & & & & \\
No.of high-pitched bleats & 5 & $2020.01^{*}$ & 22 & 672.21 \\
No.of rejections at udder & 5 & $734.58^{* *}$ & 18 & 119.94 \\
No.of threats and head butts & 4 & 1277.52 & 8 & 1117.10 \\
Lamb behaviour displays: & & & & \\
Distance by lamb towards the dam & 5 & 13.92 & 22 & 8.17 \\
Latency to first suckling & 5 & 3.93 & 15 & 2.77 \\
Suckling time & 5 & $14.92^{* *}$ & 15 & 1.13 \\
No.of suckling attempts & 5 & $384.23^{*}$ & 16 & 101.87 \\
No.of baaings & 5 & 1.80 & 22 & 2.45 \\
\hline
\end{tabular}

${ }^{\star} P<0.05,{ }^{* \star} P<0.01$

\section{Negative maternal behaviour displays:}

It can be seen (Table 2) that the highest number of high-pitched bleats were emitted by ewes whose lambs were blackened except head (72.00), followed, respectively, by ewes with completely black lambs (57.33) and lambs with black rump (50.00). Number of high-pitched bleats for blackened body lambs differed significantly $(P<0.05)$ from that of control lambs (31.33) and lambs with blackened eye region (20.00) as well as blackened head (17.00) ( Table 2). Number of high-pitched bleats towards completely blackened or rump blackened lambs did not differ from that of the control group (Table 2), although the influence of blackening on number of high-pitched bleats was significant $(P<0.05)$ (Table 3).

It is clear that number of rejections at udder was, in general, significantly $(\mathrm{P}<0.05)$ less in case of control lambs and lambs with slight darkening, i.e. blackened eye region or blackened head (Table 2). This infers that visual recognition of lambs by ewes is an important cue at the early stages of lamb's life. In the meantime, a highly significant $(P<0.01)$ effect of blackening on number of rejections at udder was found (Table 3).

No significant differences were observed among the treated groups in number of threats and head butts (Tables 2 and 3 ). Nevertheless, all lambs with completely blackened and blackened body except head received threats and head butts from their dams (Table 2). Meanwhile, blackened eye or rump lambs were threatened and butted by $33 \%$ of their dams. Whereas, $25 \%$ of dams threatened and butted black head lambs (Table 2). On the other side, no ewe threatened or butted her lamb in the untreated (control) group (Table 2). Similar results were reported by 
Alexander and Shillito (1977 b) who observed no butting or threatening with normal (unblackened) lambs, while significant proportion of ewes butted and threatened their completely blackened lambs or even head blackened ones. Moreover, Alexander (1977) showed that blackening of lambs may cause agonistic responses in some ewes.

\section{Lamb behaviour displays:}

The distance covered by lamb towards the dam is conversely proportional to that paced by dam (Table 2). Lambs blackened, whole body except head, paced significantly $(\mathrm{P}<0.05)$ longer distance towards their dams (Table 2). Lambs completely or partially blackened, including those with black rump, black eye region or head, followed, respectively. These findings may reflect the eagerness of blackened lambs to meet their dams as the later could not easily and promptly distinguish them. Dams hesitated to approach their lambs. Thus, such treated lambs paced longer distance towards their dams. Similar behaviour was recorded by Alexander and Shillito (1978 b) who noted that ewes showed marked abnormalities of their maternal behaviour such as vigorous avoidance of the approaching lamb which had been coloured by brushing pigments into the coat. However, differences in distances paced either by dam or lamb in the different experimental groups were not significant (Table 3).

On the other hand, completely blackened lambs and those with black head spent more time to first suckling than lambs of the other control and experimental groups (Table 2). This is supported by Alexander and Shillito (1977 b) who found that visual cues assisted ewes to distinguish their own from an alien lamb and that comes largely from the head region. Differences, however, among lambs of the different groups in latency to first suckling were not significant (Tables 2 and 3). Suckling time was obviously longer for unblackened (control) as well as slightly blackened (eye region, head and rump) lambs (Table 2). In this context, suckling time of $50 \%$ in completely blackened lambs and $67 \%$ of lambs with blackened body except head was significantly $(P<0.05)$ less than that of all lambs in control and other treated groups (Table 2). Differences in suckling time due to blackening were highly significant $(\mathrm{P}<0.01)$ (Table 3 ). Similar observation was reported by Alexander and Shillito (1977 b) who found that $20 \%$ of completely blackened lambs or lambs with black head were prevented from suckling during the observation period.

Blackening resulted in significant $(P<0.05)$ difference in number of suckling attempts (Table 3 ). The highest number of suckling attempts was exerted by the completely black lambs, followed, respectively, by black rump lambs (which could be easily seen at suckling) as well as black body excluding head lambs (Table 2). Less suckling attempts were done by lambs with black head and those with black region around the eyes (both could be hardly seen by the ewe at suckling) (Table 2).

Unblackened lambs (control group) emitted less number of baaings than blackened ones (Table 2). But blackening of lambs whether completely or partially did not cause significant difference in number of baaings (Tables 2 and 3 ). It is clear that vision might help the lambs, whether treated (coloured) or untreated (control), to identify their dams. 
Abd-Alla, M.S. et al.,

Consequently, lambs did not need to exhibit more care soliciting behaviour.

It could be concluded from the aforementioned discussion that maternal behaviour of ewes was negatively affected by changing the colour appearance of their lambs. Where, lambs with blackened body except head and those with completely black bodies were rejected more times by their dams. The pervious findings showed clearly how vision is an important sense in the establishment of a strong bond between dam and offspring. Terrazas et al. (1999) and Poindron et al. (2003) confirmed that visual cue plays an important role in ewe-lamb recognition.

\section{Conclusion}

Vision plays an important role in ewe-lamb bond during the early stages of lamb's life. Changes in the colour of the lamb can result in ewelamb rejection as if own lamb was alien.

\section{Acknowledgement}

The authors would like to thank Prof. Dr. G.M.Ashmawi, Professor of Sheep and Goat Production, Faculty of Agriculture, Cairo University for his kind assistance during this work.

\section{REFERENCES}

Abdel-Moneim, A. Y. and Abd-Alla, M. S. (2006). Maternal and neonatal behaviour in Egyptian sheep as affected by breed, parity and sex of lamb. In the $13^{\text {th }}$ Conference of the Egyptian Society of Animal Production, Cairo, Egypt. Egyptian J. Anim. Prod., 43 (Supplement Issue): 93-103.

Alexander, G. (1977). Role of auditory and visual cues in mutual recognition between ewes and lambs in Merino sheep. Appl. Anim. Ethol., 3:65-81.

Alexander, G. and Shillito, E. E. (1977 a). The importance of odour, appearance and voice in maternal recognition of the young in Merino sheep (Ovis aries). Appl. Anim. Ethol., 3:127-135.

Alexander, G. and Shillito, E. E. (1977 b). Importance of visual clues from various body regions in maternal recognition of the young in Merino sheep (Ovis aries). Appl. Anim. Ethol., 3:137-143.

Alexander, G. and Shillito, E. E. (1978 a). Visual discrimination between ewes by lambs. Appl. Anim. Ethol., 4:81- 85 .

Alexander, G. and Shillito, E. E. (1978 b). Maternal responses in Merino ewes to artificially coloured lambs. Appl. Anim. Ethol., 4:141-152.

Hart, B. L. (1985). The Behaviour of Domestic Animals. W.H. Freeman and Company, New York, 390 pp.

Keller, M.; Meurisse, M.; Poindron, P.; Nowak, R.; Ferreira, G.; Shayit, M. and Lévy, F. (2003). Maternal experience influences the establishment of visual/auditory, but not olfactory recognition of the newborn lamb by ewes at parturition. Dev. Psychobiol., 43:167176.

Pfister, J. A.; Astorga, J. B.; Panter, K. E.; Stegelmeier, B. L. and Molyneuxc, R. J. (2006). Maternal ingestion of locoweed I. Effects on ewe-lamb bonding and behaviour. Small Rumin. Res., 65:51-63. 
Poindron, P.; Gilling, G.; Hernandez, H.; Serafin, N. and Terrazas, A. (2003). Early recognition of newborn goat kids by their mother: INon-olfactory discrimination. Dev. Psychobiol., 43:82-89.

SAS (1998). SAS User's Guide: Statistics. SAS Inst. Inc., Cary, NC, USA.

Terrazas, A.; Ferreira, G.; Lévy, F.; Nowak, R.; Serafin, N.; Orgeur, P.; Soto, R. and Poindron, P. (1999). Do ewes recognize their lambs within the first day postpartum without the help of olfactory cues? Behav. Process., 47:19-29.

Vince, M. A.; Lynch, J. J.; Mottershead, B. E.; Green, G. C. and Elwin, R. L. (1987). Interactions between normal ewes and newly born lambs deprived of visual, olfactory and tactile sensory information. Appl. Anim. Behav. Sci., 19:119-136.

\footnotetext{
الإستجابات السلوكية للنعاج والحملان نتيجة لتغير لون غطاء جسم الحمل:

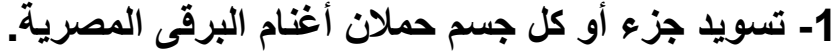

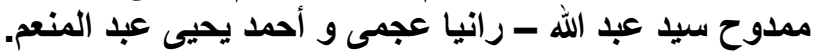
قسم الإنتاج الحيوانى ـ كلية الزراعة - جامعة القاهرة - الجيزة - مصر.

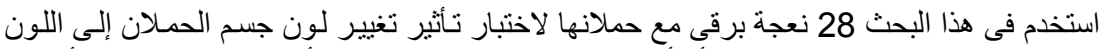

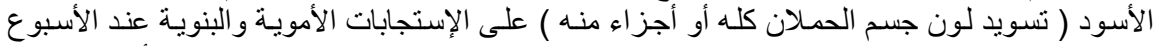

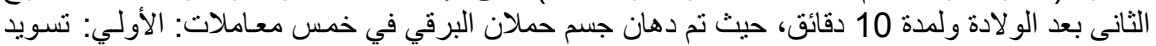

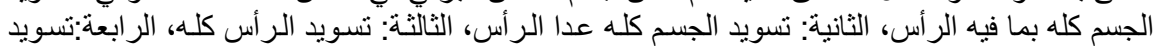

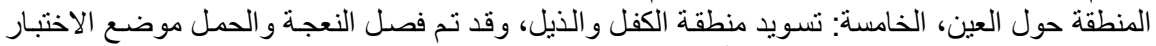

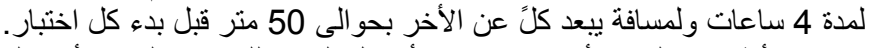

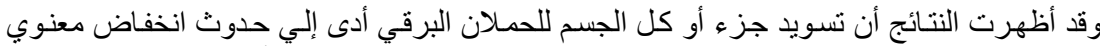

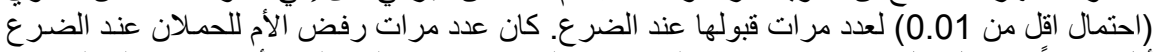

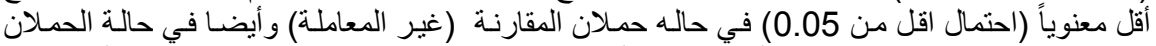

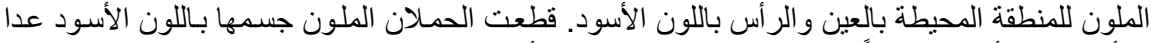

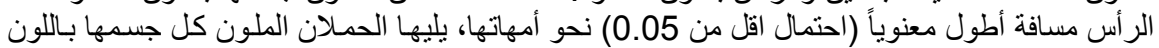

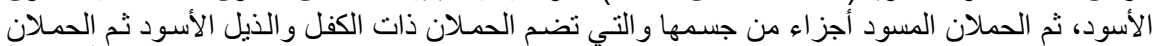

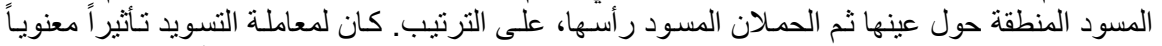

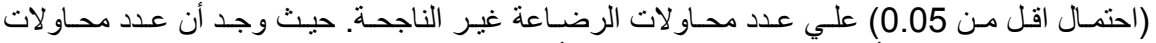

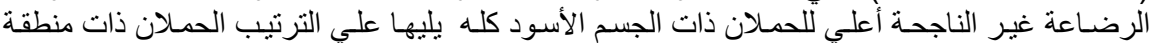

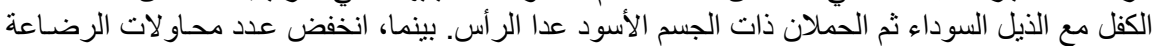

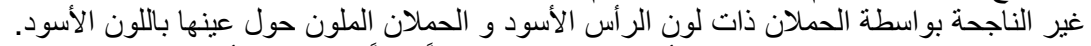

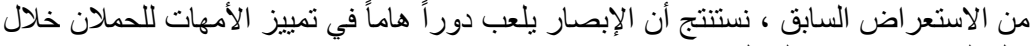

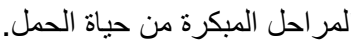

كلية الزراعة - جامعة المنصورة قام بتحكيم البحث كلية الزراعة - جامعة الازهر 
Abd-Alla, M.S. et al., 
Table (2):The effect of blackening all or a part of lamb's body on maternal and lamb behaviour displays.

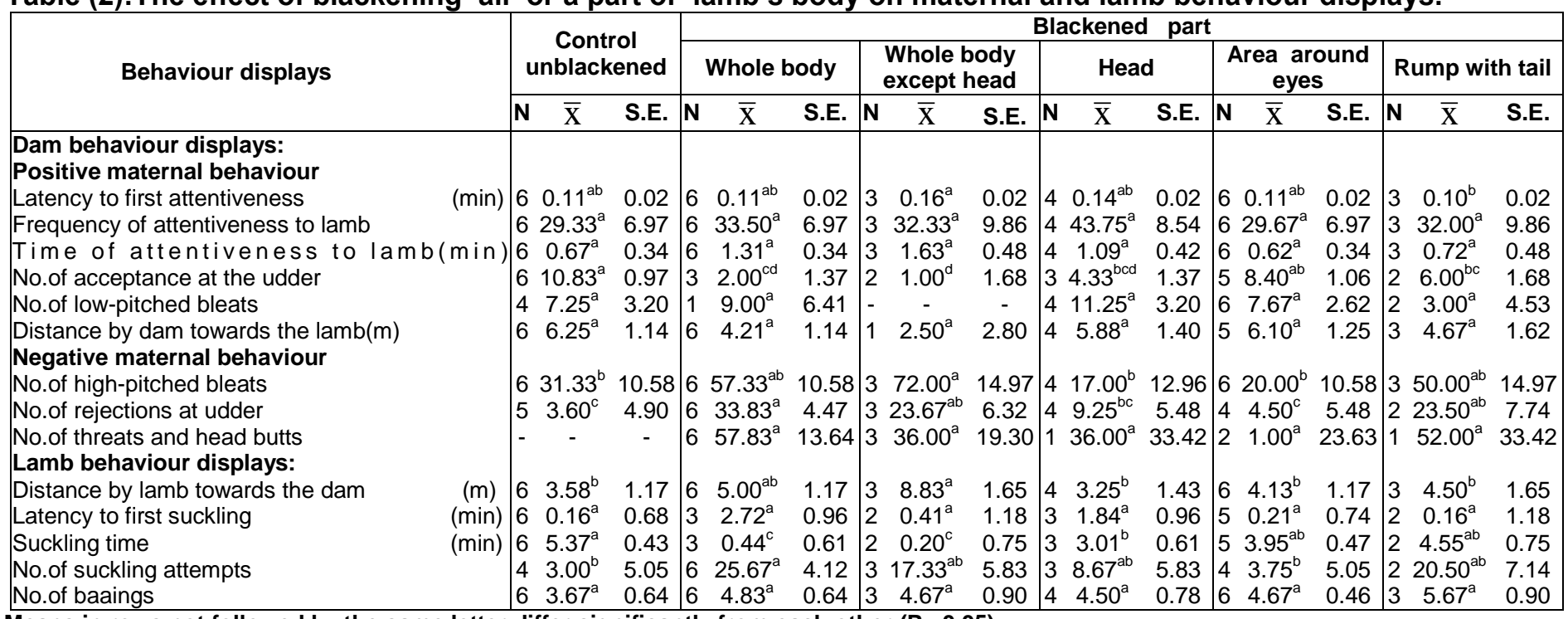

No.of baaings

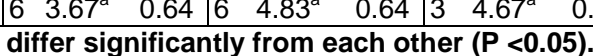

$\mathrm{N}$ : Number of animals exhibited the display. 